positron emission tomography with radio ligand [11c] FLB 457. J Clin Psychiatry 2010; 71: 793-9.

Allan Scott, Andrew Duncan Clinic, Royal Edinburgh Hospital, Morningside Terrace Edinburgh EH10 5HF, UK. Email: Fiona.J.Morrison@nhslothian.scot.nhs.uk

doi: 10.1192/bjp.197.6.499a

\section{A care pathway for schizophrenia}

Swaran Singh has recently argued for a care pathway for psychosis or schizophrenia. ${ }^{1}$ We have recently argued for a staging approach to schizophrenia. ${ }^{2}$ Such an approach argues that there are different stages in the development of schizophrenia, and that therefore different stages of the illness will require different interventions to optimise treatment, be it pharmaceutical, social or psychological. Furthermore, logically, the different stages will require different goals of treatment and different expected outcome measures. Thus, for example, the aim of treatment in the first or 'at risk mental state' stage of psychosis is to prevent psychosis developing, while the aim of the second stage, or the first-episode stage, is to end the psychotic episode and return the patient to work and education.

Staging in schizophrenia also extends to the phase of chronic illness, and here the goal will be, depending on the severity of the illness, to limit the positive and negative symptoms of the illness, to prevent relapse, and to optimise social inclusion, promoting a return to work if possible. Such a staging approach to schizophrenia is underpinned by the neuroimaging evidence, since the loss of grey matter linked with schizophrenia does start in the prodromal 'at risk' phase, becomes more prominent in the first episode, and then becomes incrementally more severe in the later stages of the disease. ${ }^{3-5}$ Furthermore, different stages of the illness appear to be mirrored in different patterns of change in such structures as the hippocampus and the amygdala ${ }^{6}$ as well as changes in pituitary volume. ${ }^{7,8}$ Thus, a 'staging approach' to schizophrenia does provide a logical framework for the development of a care pathway for schizophrenia, with different stages or phases requiring the development of specialised teams with different expected outcomes, but who will always, in each phase of the illness, strive to optimise treatment in order to achieve the best results. Hence, such a pathway may include an 'at risk mental health' team, which will attempt to reduce the rate of transition to full psychosis in patients who are developing 'prodromal' symptoms. This would be followed in the pathway by a first-episode service which will work assertively with patients so as to deal with the first episode and return patients to work and education, and at the other end of the spectrum, assertive outreach teams will work with patients who are difficult to treat who have demonstrated the most serious deterioration in functioning.

What, however, is missing in this care pathway is the treatment of those patients who are returned to community mental health teams (CMHTs) after 3 years in an early intervention service and who are not deemed ill enough to require referral to the assertive outreach teams. These constitute the majority of patients with long-term schizophrenia. Unfortunately, since CMHTs have other priorities, and indeed are oriented to dealing with patients with relatively less severe forms of mental illness, many of these patients may receive suboptimal care, sometimes consisting of the simple delivery of medication within a depot or clozapine clinic, and without the systematic delivery of psychosocial interventions. As a result, in many cases, social inclusion is not optimised as a direct result of the loss of the assertive approach to care. It is therefore small wonder that both the Lambeth Early
Onset $(\mathrm{LEO})^{9}$ and the OPUS ${ }^{10}$ services report a loss of improvement in outcomes within 5 years of first treatment, after patients have been transferred from early intervention teams to the care of CMHTs.

It is of interest that a study in Russia, ${ }^{11}$ where patients were followed up assertively for 5 years, has shown no such loss of improvement in outcomes. It is urgent that the development of ongoing assertive, specialised teams for psychosis, as suggested by Singh, should proceed in order to complete the schizophrenia care pathway. The CMHT cannot provide such an assertive service, since it is focused on other things. Seen in this perspective, recent suggestions that early intervention and assertive outreach teams should be amalgamated into CMHTs and provide elements of specialised care within the CMHTs must further confuse the focus of the CMHTs and constitute a serious misreading of the evidence.

1 Singh SP. Early intervention in psychosis. Br J Psychiatry 2010; 196: 343-5.

2 Agius M, Goh C, Ulhaq S, McGorry P. The staging model in schizophrenia, and its clinical implications. Psychiatr Danub 2010; 22: 211-20.

3 Meisenzahl EM, Koutsouleris N, Gaser C, Bottlender R, Schmitt GJ, McGuire $P$, et al. Structural brain alterations in subjects at high-risk of psychosis: a voxel-based morphometric study. Schizophr Res 2008; 102: 150-62.

4 Meisenzahl EM, Koutsouleris N, Bottlender R, Scheuerecker J, Jäger M, Teipel $\mathrm{SJ}$, et al. Structural brain alterations at different stages of schizophrenia: a voxel-based morphometric study. Schizophr Res 2008; 104: 44-60.

5 Pantelis C, Yücel M, Wood SJ, Velakoulis D, Sun D, Berger G, et al. Structural brain imaging evidence for multiple pathological processes at different stages of brain development in schizophrenia. Schizophr Bull 2005; 31: 672-96.

6 Velakoulis D, Wood SJ, Wong MT, McGorry PD, Yung A, Phillips L, et al. Hippocampal and amygdala volumes according to psychosis stage and diagnosis: a magnetic resonance imaging study of chronic schizophrenia, first episode psychosis, and ultra-high-risk individuals. Arch Gen Psychiatry 2006; 63: 139-49.

7 Pariante CM, Vassilopoulou K, Velakoulis D, Phillips L, Soulsby B, Wood SJ, et al. Pituitary volume in psychosis. Br J Psychiatry 2004; 185: 5-10.

8 Garner B, Pariante CM, Wood SJ, Velakoulis D, Phillips L, Soulsby B, et al. Pituitary volume predicts future transition to psychosis in individuals at ultrahigh risk of developing psychosis. Biol Psychiatry 2005; 58: 417-23.

9 Gafoor R, Nitsch D, McCrone P, Craig TKJ, Garety PA, Power P, et al. Effect of early intervention on 5-year outcome in non-affective psychosis. Br J Psychiatry 2010; 196: 372-6.

10 Bertelsen $\mathrm{M}$, Jeppesen $\mathrm{P}$, Petersen L, Thorup A, Øhlenschlæger J, le Quach P, et al. Five-year follow-up of a randomized multicenter trial of intensive early intervention vs standard treatment for patients with a first episode of psychotic illness. Arch Gen Psychiatry 2008; 65: 762-71.

11 Zaytseva Y. Efficacy of integrated program treatment of first episode patients versus standard care. Psychiatr Health 2008; 10: 51-7.

Mark Agius, South Essex University Partnership Foundation Trust, and Department of Psychiatry, University of Cambridge, Addenbrooke's Hospital, Hills Road, Cambridge CB2 2QQ, UK. Email: ma393@cam.ac.uk

doi: 10.1192/bjp.197.6.500

Author's reply: I am grateful for Dr Agius' comments and entirely agree that a staging approach allows the development of a comprehensive care pathway for psychotic disorders. With such an approach, the most efficacious and potentially less harmful interventions can be appropriately targeted at an earlier clinical stage of an emerging illness. Such a staging model is widely used in medicine and has recently been described as a heuristic framework for intervening early in all youth mental health problems. $^{1,2}$

Half of all adult mental disorders begin in late adolescence, usually with an initial presentation of non-diagnostic symptoms. Mental health services, especially community mental health teams (CMHTs), offer interventions only when an illness is severe 